\title{
Framing Harm: Legal, Local and Anthropological Knowledge in the Context of Forced Migration
}

\author{
By Shannon Morreira (University of Cape Town)
}

The southern African state of Zimbabwe, which borders South Africa, has undergone a decade of severe political and economic instability. Migration from Zimbabwe to South Africa has been extensive, and continues even with the slight improvements that Zimbabwe has seen since 2009. In this paper I use migration from Zimbabwe to South Africa as a case study through which to explore knowledge creation within the field of forced migration and human rights, and within the field of anthropology. What are the similarities and differences between local, legal and anthropological knowledge of rights violations in the context of crisis? How do individual, subjective tales of suffering and violation become, or fail to become, supposedly objective 'evidence', and how might legal evidence differ from Zimbabwean moral knowledge of harm? In this paper I consider the difficulties of translating experiences of violation into legal and anthropological language and knowledge.

\section{'Rights, not Wrongs': an Introduction}

There are no "neutral" words and forms - words and forms that belong to "no one"; language (is) shot through with intentions and accents... All words have the "taste" of a profession, a genre, a tendency, a party, a particular work, a particular person, a generation, an age group, the day and hour. Each word tastes of the context and contexts in which it has lived its socially charged life; all words and forms are populated by intentions. (Bhaktin, 1981: 293)

In 2007, whilst engaged in fieldwork for my Masters degree, I attended a protest held at the Home Affairs Refugee Centre in central Cape Town, South Africa. I was present both as researcher and as activist. My research was focused on Zimbabwean undocumented migration to South Africa, and my activist work sprung from my own position as a Zimbabwean living, albeit legally, in South Africa for the same sorts of reasons as the undocumented migrants with whom I worked - namely, to escape from an escalating political and economic crisis. As such, wearing the two hats of intimacy and distance that are required by activist anthropology, I was present when a group of Zimbabweans began the process of writing on banners provided by the activist group of which I was a member. A group of ten of my informants and friends clustered around an old sheet that was placed on the pavement outside the gates of the Centre, with one man brandishing a paintbrush and a tin of red paint. He squatted down, dipped the brush in paint, held it over the sheet... and then hesitated. 'What do I write?' he asked, 'What are we saying to these people?'

There was a moment of silence, followed by a plethora of answers - 'We are tired of waiting for an appointment'; 'We are not animals that must wait in the rain for them to let us inside'; 'We want to be allowed to stay here because things are so bad at 
home'; 'We are tired of being illegal when we have done nothing wrong'; 'We want to say that we are suffering, here and at home'; 'We have had enough of Mugabe and Mbeki' (the respective presidents of Zimbabwe and South Africa at the time); and 'We would not be here if we could make a living at home.' The man looked at his companions and said, 'But I can't write all those things on a banner. It must be catchy, quick - but it must say why we are here.' A pause whilst people tried to think of something catchy, something 'quick' - and then one man said 'Just write, "We want human rights, not human wrongs", or "No rights in Zimbabwe, no rights in South Africa." Everyone in the group nodded approvingly and the two banners were made. A language of human rights, it seemed, was able to speak across disparate intentions to provide, if you will, a summarizing symbol (Ortner, 1973) that could encompass suffering, tiredness, illegality, personhood, politics, economics and morality (both 'here' and 'at home'), and 'quickly' transpose these to the powerful realm of legal language. Individual, subjective knowledges of what it meant to be an illegal immigrant were rapidly reordered into the (supposedly) more objective, and thus weightier, realm of knowledge that we categorise as human rights discourse.

That brief moment outside Home Affairs thus seemed to me to provide a window into the entanglements (Mbembe, 2001) at play when the notion of human rights is called upon. Throughout my fieldwork in 2007 and 2008, 'human rights' (or just 'rights') were invoked again and again, in contexts as incongruous as the christening of a child or the personal recounting of a life history marred by political violence. It thus seemed to me that 'rights talk' (Mamdani, 2000), in this context, had become a powerful way of ordering experiences, and of ensuring that those experiences could be legitimised and shared with others.

In 2010, I returned to the field as a doctoral student, focusing specifically on the ways in which notions of rights were being mobilised by Zimbabweans in South Africa and at home. In this paper I use migration from Zimbabwe to South Africa as a case study through which to explore knowledge creation within the field of forced migration and human rights, and within the field of anthropology. What, then, comprises 'knowledge' or, for the particular purposes of this paper, a knowledge of human rights? In this paper I take knowledge of rights to constitute familiarity with, or perceived understanding of, the notion of the rights that are accorded to people by the simple virtue of their being a person. I argue that this knowledge is based both on personal experience (individual knowledge), and on culturally transmitted (shared) information. This fluid mix of the shared and the personal means that there is more than one way of knowing rights, and thus that ways of knowing are situational. Further, the processes of knowledge transmission are also subject to contestation, and knowledge is thus imbued with power relations. In the case of asylum seeking, some kinds of knowledge are more powerful than others, as is explored below.

What, then, are 'human rights'? On one level, the answer, whilst not simple, is at least easily definable - human rights constitute a set of morals, a normative guide for behaviour towards others, which have been encoded in international law. In Africa, for example, 'human rights' are those things which have been written, in legalese, into the African Charter on Human and People's Rights (ACHPR) as adopted by the Organisation of African Unity (OAU) in 1981 (Akokpari and Zimbler, 2008), and to which, as African Union members, Zimbabwe and South Africa are signatory. How many people, however, are well versed in such legal documents? Legal charters 
reflect a domain of a specific sector of the elite - yet 'human rights' as a phrase is one which is drawn upon by many more diverse sectors of the populace, from other elites to, as the above example shows, the deeply marginalised. Notions of 'human rights', then, have to reflect more than that which is encoded in Charters - beyond this legal discourse lies a realm of rights that is truly 'socially charged' (Bhaktin, 1981:293), a realm that is, to mix my theorists and borrow a phrase from Wilson (2006; cf. Appadurai, 1986), immersed in the social life of words.

The data in this paper is drawn from primary research I have undertaken over the last three years from 2007 to 2010. Using case studies and my own experiences in the field (both as anthropologist and as activist against the political crisis in Zimbabwe), I trace how people struggle to present their individual, subjective stories of violation in such a way that they constitute adequate 'evidence' in the contexts of formal interviews at Home Affairs for the purposes of seeking asylum, and the ways in which, more often than not, this ends in failure. Secondly, I go on to explore how this evidential based way of knowing differs from Zimbabwean informants' moral knowledge of harm, though both are presented as a way of knowing rights, or, conversely, knowing a violation of those rights. Finally, I consider the ways in which the kinds of knowledge that have legitimacy within anthropology allow for access to other ('local') ways of knowing, whilst simultaneously bowing to the (global) epistemological pressures that push toward categorisation in particular ways. It is first necessary, however, to briefly provide the socio-political context of migration, particularly as the outcome of attempts to seek asylum often depend upon official South African perceptions of the political context in Zimbabwe.

\section{The context of migration}

Zimbabwe, hailed in the 1980s and early 90s as one of Africa's 'success stories', has undergone a decade of political and economic decline. The country has two major political parties, the liberation party Zimbabwe African National Union-Patriotic Front (ZANU-PF) which came into power at independence in 1980, and the newer Movement for Democratic Change (MDC), which was formed in the late 1990s in opposition to ZANU-PFs excesses. Beginning in 1999, ZANU-PF implemented a series of policies that led to an economic collapse that saw hyperinflation reaching $7.96 \times 10^{10}$ percent in November $2008-$ a rate that effectively meant prices doubled every 24 hours (Hanke and Kwok, 2009). The lived effects of this were extreme, and for many, survival was only possible through remittances sent in foreign currency from family members outside the country. The period has also seen a decline in democratic freedoms and a correspondent increase in political violence. The implementation of acts such as the Public Order and Security Act (POSA) allowed the state a large degree of control over people's actions. Since 2000, three sets of elections have been held, all of which have been accompanied by electoral irregularities - and by large scale violence, torture and rape of those perceived as supporters of the opposition. In 2009, a power sharing deal (the Global Political Agreement or GPA) was brokered by South Africa between the two parties, but subsequent events have shown ZANU-PF to still wield the majority of power. Regionally, however, the GPA is still recognised as legitimate.

South Africa, as a bordering country and as the strongest economy in the region, has obviously been affected by the Zimbabwean crisis. South Africa has engaged with 
ZANU-PF throughout the last decade, initially through the then South African President Thabo Mbeki's heavily criticised policy of 'quiet diplomacy'. This policy ultimately led to the GPA, which is today monitored by current President Jacob Zuma's government. On a more local level, South Africa has had to deal with an influx of asylum seekers, and found its Home Affairs Refugee Reception Offices unable to cope with the demand, leading to protests of the sort I outlined above. Even where asylum seekers were able to get an appointment, many of the reasons asylum seekers gave for seeking asylum were not considered valid, as I will explore further below, and resulted in their being labelled as illegal economic migrants (Morreira, 2010). At the time of writing, South Africa is in the process of implementing a temporary special dispensation for Zimbabwean migrants, which enables previously undocumented economic migrants to legalise their status through the granting of a work visa. For the purposes of this paper, however, I am concerned with those Zimbabweans who visited Home Affairs in the hopes of being granted refugee status, rather than a special dispensation permit - those who, in other words, viewed themselves as forcibly displaced by the Zimbabwean situation and who thus drew upon local and legal moral knowledges as a means of seeking a security of place.

\section{Narratives of harm: from personal suffering to public knowledge}

I first met Chenai ${ }^{1}$, a 26 year old chiShona woman from a small town in central Zimbabwe, in Cape Town in early 2010, at the paralegal clinic in which I was working at the time. This small, badly funded clinic provided free legal advice to refugees and asylum seekers. Chenai came to see us because she had received a letter telling her that her application for asylum was unfounded, and she had thirty days to appeal or to leave the country. She and I thus met because she had tried to find a way to fit her narrative, which has elements of both political and economic motivations for crossing the border, into the bureaucratic framework of asylum seeking - and failed. Her story of migration and displacement is thus a good place to begin a conversation about the ways in which individual experiences become ordered in various domains of knowledge.

In January 2008, Chenai gave birth to her first child, a daughter whom she named Rumbidzai. She was newly married, and living with her in-laws while her husband David looked for work in Harare, a five hour bus ride away. Economically, things were extremely difficult and the family often went hungry. At the end of March 2008, the country was holding presidential and parliamentary elections, and because of this, there was an increase in political intimidation and violence across the country. In midMarch, Chenai was walking home from a nearby house where she had gone to fetch water - municipal water had not been available for weeks and so the neighbourhood relied on the one property that had a borehole. As she was carrying a heavy load, she had left her baby at home with her mother-in-law. On her way home, Chenai encountered a group of young men who were chanting election songs. They forced her to walk with them to a rally that was being held a few kilometres away. Chenai asked them if she could go home to drop off the water first, 'but they made me pour it out on the road. I wanted to go back to get my child, so then I said that is why I really want to go back. They said I was lying so I wouldn't go to the rally - so they did not let me go home.' Chenai was held at the rally for close to 6 hours, having to sing and

\footnotetext{
${ }^{1}$ I use pseudonyms throughout this paper at the request of my informants.
} 
dance in praise of ZANU-PF in order not to draw attention to herself. 'But you know, I did not care at all about politics. I just wanted to get home to my baby, who I knew was very hungry and who needed me to feed her.' Chenai leaked breast milk onto her shirt at the rally, and was very embarrassed. An older woman lent her a jersey to cover herself. Eventually, the rally was over and Chenai could go home to a hysterically hungry Rumbidzai. Chenai remained in Zimbabwe over the election period and for the rest of the year but when her husband suggested they try to move to South Africa for economic reasons she agreed, 'because the politics in Zimbabwe nearly killed my child of hunger.' David left first, and Chenai followed a few months later. Her movement across the border was thus motivated by politics and by a failing economy, reasons that she and her husband thought might grant them asylum in South Africa.

In 2007, when I first started working with newly arrived Zimbabwean migrants, the expectation of most of my informants had been that upon telling their stories to representatives of the South African state, they would access refugee status, and thus that narratives of suffering could be utilised as a resource that would enable legal access to South Africa (Morreira, 2010). In the words of one informant, Simba, 'we thought they would see that if we stayed at home we would be suffering too much, that we might even die.' In most cases, this suffering was socioeconomic, not political. By the time of Chenai's arrival in late 2008, however, it was obvious to Zimbabweans that it was not so easy. Migrants had envisioned sharing their experiences in Zimbabwe in a formal way with representatives of Home Affairs and thus interacting in some way with formal refugee law. What most had not envisioned was telling those same stories on other occasions - to other legal aid or activist organisations when their visits to Home Affairs failed, or to myself as an anthropologist. Often, it was the inadequacy of those stories within the formal framework of refugee law, and within the informal unsuccessful bureaucracies within which those laws are played out, that led them to both those situations. Let us look at the ways knowledge comes to be ordered in each of those fields.

\section{Refugee Law and 'the evidence'}

Internationally, human rights charters recognise both the political and the socioeconomic as basic rights. A historical analysis of the legal discourse of rights shows that the international architecture of human rights can be broken down into categories, or generations, each of which reflects, in the 'inalienable' rights it encodes, the historical moment from which it originated. First generation rights, promulgated in the wake of World War II, are thus mainly concerned with political rights, and the basic security of persons (Messer 1993; Robertson, 2006). The next generation of rights, as Messer (1993) notes, carried the influence of socialism in that they are concerned with the socioeconomic: rights in this conceptualisation include ideas around working conditions, rights to a standard of living that ensures health, rights to education, and special rights for women and children. Though these rights exist at the same level as first generation rights on paper, it is more difficult to prove direct responsibility for a violation of the socioeconomic, and there is thus not the same legal precedent as there is for political violation. Most states, furthermore, do not accept socioeconomic reasons as valid for refugee status. Debates in the field of rights law have emphasised the necessity of a holistic approach to rights, which does away with different 'generations' and recognises the ways in which all rights are intertwined and 
dependant upon one another (Haas, 2008). At the level of asylum seeking, however, a violation of the economic and a violation of the political carry different entitlements.

Zimbabwean migrants' perceptions of suffering as a resource that would allow for legal access to South Africa were thus shown on many occasions to be erroneous. Asylum seekers quickly learned that it was not enough to expect that officials would 'see' the dangers of remaining in Zimbabwe through the sorts of empathetic solidarities that statements such as Simba's hinge upon. Instead, experiences of suffering needed to be ordered in such a way that narratives reflected the categories that Home Affairs officials accepted as legitimate. Thus, in Chenai's application, she had emphasised both the fear and suffering she experienced during the election rally, and the fact that the family were unable to survive economically, drawing both on political and socio-economic factors in the hope that this would satisfy the stringent application criteria. Chenai's story exemplifies the ways in which the political and the socio-economic are entangled - it was, after all, a socioeconomic violation, the absence of water, that put her in the path of political danger. Chenai's claim was rejected as unfounded, however, on the grounds that her life was not deemed to be endangered were she to return to Zimbabwe.

Her husband, David, who had applied for asylum before Chenai's arrival in South Africa, had also been rejected as unfounded. In his interview with a refugee reception officer, he had emphasised that he was unable to earn enough money to feed and clothe himself, his wife and his child, and that he could not afford basic medications if one of the family were to get ill - 'I said to him, even if I was to find five jobs with inflation as it is I would still be a starving billionaire. But how can I find even one job with unemployment above 80 percent? But to him that wasn't enough violation of my rights. I got a letter saying my application was unfounded.'

Both Chenai and her husband were deemed economic migrants, not refugees. In a legal setting, this type of naming is extremely powerful. As I have argued elsewhere (Morreira, 2010), asylum seekers' livelihoods rest on whether they are categorised by the state as 'displaced' or as economically 'mobile'.

In a formal bureaucratic setting, then, rights talk alone does not carry enough weight. The rights that are spoken of have to fit within the 'correct' categories of violation, and thus within a strictly policed domain of knowledge. Thus, though socio-economic rights such as the right to health and education are protected by human rights charters and recognised by international law, a violation of these rights is not viewed in the same light as political violations, and such violations do not form grounds for seeking asylum. Scott (1998), in his analysis of state structures and institutions, argues that the state is only able to perceive people within the bounds of the categories it has created, and that bureaucrats are not able, due to the constraints of the system, to recognise anything outside of these closely specified boundaries. As Kihato (2004:280) phrases it, 'anything not in the required format cannot be understood by the state.' I will return to this disjuncture between notions of what constitutes a violation below where I discuss the discrepancies between Zimbabwean moral knowledge of harm, and that accepted as valid within other spheres.

In Chenai and David's case then, an application for refugee status was unsuccessful on the basis of the sort of claim that was made. Even, however, where people's 
narratives 'should have ticked all the right boxes and got them a refugee permit', in the words of a lawyer I interviewed who worked in a refugee legal aid clinic, refugee status was often denied on the basis of insufficient evidence. For example, in early 2010 I met Amos, who came to the legal aid clinic after having received a letter informing him that his application had been rejected as unfounded. Amos had been a ward councillor for the opposition MDC in an urban district of Zimbabwe, and had fled from political violence during the 2008 elections. Upon being interviewed by a refugee reception officer, he was asked for written proof that he was a ward councillor, which he did not have. When Amos received his rejection letter, it stated that the burden of proof rested with the applicant, and that he had failed to provide such proof.

From the macro level position of the South African state it makes sense that evidence is needed before the state can know the 'truth' of a claim. From the subjective position of asylum seeker, however, this kind of evidence based knowing goes against the grain. Amos, who was well educated and erudite, was able to articulate this in ways that other asylum seekers did not, using legal discourses to criticise the system 'they talk here in South Africa of their amazing constitution, and of the right to dignity, but what dignity is it to treat me like a liar after I have run? Where is the dignity in making me provide a paper like a child taking a sick note to school?' In addition, Amos was further incensed as his rejection letter went on to outline the unity agreement in Zimbabwe, saying that the country was now stable. But, he said, he had heard from a friend the previous week that things were still dangerous - 'there were further beatings in my same ward last week. I ran away because of those people. And those people are still running around. Myself, I have no faith even in the police officers, those ones were the ones who were torturing, arresting. I have no faith in the power sharing. It is still the same. I suffered there from 1999, and if I hadn't gone I would still be suffering now.' This personal knowledge, however, did not bear the same weight as official knowledge within the region about the Zimbabwean situation. Amos was unbelievably angry as he read out the section of letter dealing with political stability. 'They want my evidence that I am MDC,' he raged, 'well, I want their evidence that Zimbabwe is stable. I reject that claim as unfounded.'

I have found it impossible to forget Amos's anger. His words highlight the hierarchies of power present in knowledge creation and transmission - though the South African state has the power to demand evidence for Amos's claim, he cannot ask for evidence regarding the safety of Zimbabwe in return. Through this knowledge, furthermore, the state attempts to regulate Amos's movement. In Foucauldian terms, therefore, we must recognise 'that power and knowledge directly imply one another; that there is no power relation without the correlative constitution of a field of knowledge, nor any knowledge that does not presuppose and constitute at the same time, power relations' (Foucault, 1977:27).

Amos's words starkly illuminate the interstices between official, often bureaucratic, ways of knowing and the personal, and emotional, ways of knowing harm that asylum seekers carry with them. Let us turn, then, to an examination of informants' moral knowledge of rights and violation. 


\section{Local knowledge of harm: what constitutes the rights of a person?}

One day in 2008 an informant said to me, 'If I am here to prevent my family from starving, how am I different to someone here running away from imprisonment or torture by ZANU-PF? I am also running away from ZANU. I am also fulfilling my rights if I am trying to keep my family.' I used this quote in my Masters thesis, though I left out the final sentence of it, as it seemed extraneous, an additional emphasis on rights that was not necessary. It is only recently, after having many more conversations with Zimbabweans that focus specifically on ideas of human rights (thanks to the luxury of doctoral funding and additional research time) that I have come to fully understand what he was telling me, and the importance of the sentence I so idly discarded from my finished product. I got part of the way there, arguing that migrants held that South Africa had a moral obligation to provide sanctuary, and maintained that, though they may be categorised as illegal, it was not due to any actions of their own, but rather due to inaction by the South African state. I knew that significant amounts of time and resources were devoted to attempting to gain access to Home Affairs to begin the process of seeking asylum in order to avoid illegality. I reproduced the following quote from a female informant - 'I am not a criminal, even though they can arrest me if they catch me here. I know in my heart that I have done nothing wrong, I have done nothing that I am ashamed of before God. I may be illegal, but I am not a criminal' - in order to argue that state laws pertaining to migration, therefore, were not coterminous with morality, and that crossing borders might be an illegal act, but it was not an immoral one (Morreira, 2009). Re-reading these quotes in light of my current knowledge, however, shows the ways in which I produced them as evidence for half of the story, whilst missing a central element of local knowledge that I held, but that I did not carry over into notions of human rights.

What I had not recognised was the role played by social relationships in the creation of the person in Shona culture, and the way this was translated by my informants into rights talk. In the Shona context, to be human is to be part of a web of social relationships - one is not a person without the intricate connections one holds to other people. To be human is to maintain relationships through, for example, caring for family members, or paying bridewealth (see Bourdillon, 1976). These are not things international law would claim as basic rights. These sorts of relationships, however, are taken by my informants as an inherent right of the person, and to be prevented from fulfilling them by political or economic reasons is thus translated from Shona into English, and into the weighty realm of legalese, as an infringement of human rights.

The assumptions about what it is to be a person made by the law and made by my informants therefore differed significantly. Engelke (1999) has made this point in light of a discussion of rights and homosexuality in Zimbabwe. A perusal of Shona philosophy also shows that notions of the rights of the person are situated in relationships (see Mawere, 2010; Chimuka, 2001). The South African state's knowledge about human rights, and Zimbabwean asylum seekers' knowledge about the rights of a human are therefore not the same. Notions of human rights are therefore localised and varied, a point increasingly recognised by anthropologists (for example, Merry, 2006; Wilson, 2006) but not by refugee law. The danger occurs where we use the same terminology as shorthand for very different sorts of knowledge. Tsing (2005) terms this friction, the 'zones of awkward engagement 
where words mean something different across a divide, even where people agree to speak' (Tsing, 2005: xi).

This sort of example, which highlights the particular over the universal, is not new in anthropological debates over human rights. It is only comparatively recently that anthropologists have felt comfortable enough to bring their methods and means of social examination to the field of rights. This tardiness was not because of a lack of interest, but rather due to a disciplinary limitation that resulted from shared anthropological knowledge about cultural relativism. The argument ran that anthropology, as a culturally relative discipline, could not condone the universality of basic rights. Anthropologists, therefore, avoided examining rights. The field has now shifted, however, in that the cultural relativist argument against universal rights came to be seen as reliant upon an idea of culture as static and homogenous. As such, the relativist position did not take into account power differentials within any one society or group. An epistemological shift in how we view culture, therefore, allowed for anthropologists to engage with human rights.

Anthropologists studying rights, such as Preis (1996), Merry (2003), Messer (1993) and Wilson (2006) noted, therefore, that debates around relativism with regard to human rights draw on a refuted notion of culture. Our anthropological knowledge of what is 'true' has changed. Thus, as Ortner (1984) has argued with regard to culture, there is a need in the study of human rights to move to the ways in which it is embedded in practice, and the ways in which power affects meaning making, or, conversely, the ways in which accepted meanings affect power or marginality.

There was thus a disciplinary move away from a cut and dried debate between either relativism or universalism. In keeping with this, my view is thus that the most pertinent point to be taken from the Shona example given above is not that it reflects a difference of culture that is inconsistent with a universal notion of rights - but rather that this local understanding of personhood is translated by my informants into the universal language of human rights. The local and the universal are thus not incommensurate, though they are enmeshed in power relations.

To speak of hardship in terms of a violation of basic human rights accords it a legitimacy that is otherwise hard to come by. There is thus value in the assumed universality of rights, in that it provides a great deal of globally condoned cultural capital. Rights talk is a resource, and the power of that resource lies in the fact that we agree that we all share basic rights. There is also a need, however, to recognise the ways in which local notions of rights might be broader than this universal prescribed minimum. Asylum seekers interactions with the South African state are thus complex, and draw upon local and global ways of knowing.

This complexity cannot be easily or quickly accessed - which brings us to anthropological techniques, in that they allow for this sort of knowledge. In closing, then, let us turn to a consideration of the ways in which anthropology comes to know.

\section{Other ways of knowing: anthropology and the intersubjective}

Domains of knowledge will always have that which is considered legitimate knowledge, and that which is not. Merry (2005) argues, for instance, that 
anthropological interest in human rights is only possible as anthropology has shifted from studying processes on the fringes of modernity to those processes that are at its centre. Goodale (2006) has noted that anthropology is well positioned to consider the ways in which human rights discourse 'captures the constellation of philosophical, practical, and phenomenological dimensions through which universal rights, believed to be entailed by a common human nature, are enacted, debated, practiced, violated, envisioned and experienced' (Goodale, 2006:490). Universal discourses become localised in varied ways, and an anthropological way of knowing allows for an examination of practice. This examination results in an ethnographic argument such as the one I have presented here. It is thus not only my informants who use translation as a means of transferring knowledge. Translation is central to the anthropological way of knowing.

In order to be in a position to translate, however, we expect ourselves as anthropologists to be able to walk in at least two worlds. Indeed, with the rise of multi-sited ethnography and the increased disciplinary acceptance of examining transnational flows, we often expect ourselves to walk in multiple worlds, and to talk in multiple voices. When I first started long-term fieldwork, a colleague with far more experience warned me that I would need 'to learn to be comfortably schizophrenic.' After a few years in the field, this seems to me to be extremely good advice, particularly as there is, in my case, constant slippage between 'the field' and 'home', and between my identities as anthropologist, activist, Zimbabwean, and South African. There are, of course, times when there is more friction than comfort - but these are often the times that allow for insight into the disjunctures between these ways of knowing. When we feel discomforted, we know that our fieldwork is going well because we are learning to walk between worlds.

Anthropological knowledge thus rests to a great degree on the legitimacy that is provided by experience (cf Scott, 1991) - participant observation and immersion into long term fieldwork all assume the anthropologist to, at the very least, have 'been there', wherever there may be, over a long period of time, and thus to have access to another way of knowing. The examples I have used so far to argue that there is a disjuncture between rights as known in South African law and rights as known by Zimbabweans trying to access that law, are only possible because of an anthropological way of knowing that allows for time and prioritises qualitative research.

Beyond research techniques, moreover, ethnographic knowledge of this sort is only possible because of shifts within anthropological thought that allow for a privileging of 'soft' facts over 'hard' (Hastrup, 1993:727), and of subjectivities over objectivities. The true strength of anthropological knowledge seems to me, therefore, to be its ability to access the intersubjective in order to assess both the assonances and dissonances of modernity. Thus Descola (2005:73) argues that anthropological knowledge is 'a novel form of understanding the otherness of others'.

It is also now possible to be both anthropologist and activist, and thus to sit at interstices that would previously have been viewed as unscholarly. I feel that from these interstices, we can gain the sorts of knowledge that allow for an informed activism. In my case, this is an activism that positions itself against the violations, in their broadest sense, that are occurring in Zimbabwe - but that also allows for a 
critical eye to be kept on the discourses that people are working within. Thus, like Veena Das, 'I try to defend a picture of anthropological knowledge in relation to suffering as that which is wakeful to violence wherever it occurs in the weave of life, and the body of the anthropological text as that which refuses complicity with violence by opening itself to the pain of the other' (2007: 211).

\section{Acknowledgements}

The research on which this paper is based would not have been possible without the support of the South African National Research Foundation (NRF), Grant No. 69324, and the David and Elaine Potter Foundation. I would like to thank both organizations. The views reflected here are my own. With thanks to all my informants, to Gemma John for her useful comments regarding translation, to the insightful commentary of an anonymous reviewer, and to Imke Gooskens and Dr. Fiona Ross for reading an early version.

\section{About the Author}

Shannon Morreira is a $\mathrm{PhD}$ candidate in the department of Social Anthropology at the University of Cape Town. Her recent publications are concerned with Zimbabwe's economic and political crisis and the resultant migration of Zimbabweans to South Africa. Her current research is focused on the ways in which ideas of human rights are being mobilised by Zimbabweans during the country's political crisis.

\section{Bibliography}

Akokpari, J. and Zimbler, D. (eds) (2008), Africa's Human Rights Architecture, Johannesburg: Centre for Conflict Resolution and Jacana.

Appadurai, A. (ed) (1986), The Social Life of Things: Commodities in Cultural Perspective, Cambridge: Cambridge University Press.

Bhaktin, M. (1981), The Dialogical Imagination, C. Emerson and M. Holquist (trans.), Austin, Texas: University of Texas Press.

Bourdillon, M. (1987), The Shona Peoples, $3^{\text {rd }}$ Edition, Gweru: Mambo Press.

Chimuka, T. (2001), 'Ethics Among the Shona', Zambesia, XXVIII (i) pp. 23-37. (Available online at ir.uz.ac.zw:8080/jspui/bitstream/10646/500/1/2-Chimuka.pdf)

Das, V. (2007), Life and words: Violence and the Descent into the Ordinary, Berkeley: University of California Press.

Descola, P. (2005), 'On Anthropological Knowledge', Social Anthropology, 13 (1) pp. 65-73.

Engelke, M. (1999), 'We Wondered What Human Rights He was Talking About: Human Rights, Homosexuality and the Zimbabwe International Book Fair', Critique of Anthropology, 19 (3) pp. 289-314. 
Foucault, M. (1977), Discipline and Punish: the Birth of the Prison, A. Sheridan (trans.), New York: Vintage Books.

Goodale, M. (2006), 'Toward a Critical Anthropology of Human Rights', Current Anthropology, 47 (3) pp. 485-511.

Kihato, C. (2004), 'NEPAD, the City and the Immigrant', Development Update: The City and Its Future? The Eternal Question, 5(1): 267-286.

Haas, M. (2008), International Human Rights: A Comprehensive Introduction. London: Routledge.

Hanke, S. and Kwok, A. (2009), 'On the Measurement of Zimbabwe's Hyperinflation', Cato Journal, 29 (2): 353-364. (Available online at http://www.cato.org/pubs/journal/cj29n2/cj29n2-8.pdf)

Hastrup, K. (1993), 'Hunger and the Hardness of Facts', Man, (28): 727-739.

Mamdani, M. (ed.) (2000), Beyond Rights Talk and Culture Talk: Comparative Essays on the Politics of Rights and Culture, Cape Town: David Philip.

Mawere, M. (2010), 'On Pursuit of the Purpose of Life: The Shona Metaphysical Perspective', The Journal of Pan African Studies 3 (6): 269-284 (Available online at www.jpanafrican.com/docs/vol3no6/3.5OnPursuit.pdf)

Mbembe, A. (2001), On the Postcolony, Berkeley: University of California Press.

Merry, S. (2003), 'Human Rights Law and the Demonisation of Culture', Political and Legal Anthropological Review, 26 (1): 55-77 (Available online at http://www.aals.org/am2004/merry2004.pdf )

---- (2005), 'Anthropology and Activism: Researching Human Rights Across Porous Boundaries', Political and Legal Anthropological Review 28 (2): 240-257.

---- 2006. 'Transnational Human Rights and Local Activism: Mapping the Middle', American Anthropologist, 108 (1): 38-51.

Messer, E. (1993), 'Anthropology and Human Rights', Annual Review of Anthropology, 22: 221-249.

Morreira, S. (2009), Seeking Solidarity. Categorisation and the Politics of Alienism in the Migration of Zimbabweans to South Africa, University of Cape Town: Unpublished Masters Dissertation.

---- (2010), 'Seeking Solidarity: Zimbabwean Undocumented Migrants in Cape Town, 2007', Journal of Southern African Studies, 36(2): 433-488.

Ortner, S. (1973), ‘On Key Symbols’, American Anthropologist, 75 (5): 1338-1346 
---- (1984), 'Anthropology Since the Sixties', Comparitive Studies in Society and History, 26 (1): 126-166.

Preis, A-B. (1996), 'Human Rights as Cultural Practice: An Anthropological Critique', Human Rights Quarterly, 18 : 286-315.

Robertson, G. (2006), Crimes Against Humanity. The Struggle for Global Justice, ( $3^{\text {rd }}$ edition) London: Penguin.

Scott, J. (1991), 'The Evidence of Experience', Critical Enquiry, 17: 773-797.

Scott, J. (1998), Seeing Like a State: How Certain Schemes to Improve the Human Condition have Failed, New Haven: Yale University Press.

Tsing, A. L. (2006), Friction: An Ethnography of Global Connection, Princeton: Princeton University Press.

Wilson, R. (2006), 'Afterword to "Anthropology and Human Rights in a New Key": The Social Life of Human Rights', American Anthropologist, 108(1): 77-83. 